\title{
Younger Age Groups and the Next COVID-19 Wave
}

\author{
Alamin Alkundi* and Rabiu Momoh \\ William Harvey Hospital, Ashford, Kent, United Kingdom
}

\begin{abstract}
As lockdown measures to control the COVID-19 virus are being eased in a lot of countries, (including the United Kingdom), the potential of a second wave of this infection spread remains a possibility as most countries have not been able to achieve herd immunity from this virus. We have explored the potential risk of younger age groups being more affected in a second wave of this virus and made recommendations.
\end{abstract}

\section{Introduction}

The impact of the COVID-19 pandemic on the world today is glaringly evident and palpable. It has disrupted life as many would normally know it, disrupted economies, maimed individuals and claiming lives in hundreds of thousands already. The world has stood up to its challenges by deploying pharmaceutical and non-pharmaceutical interventions, by means of which we have scraped by so far [1].

Lockdown measures deployed have been noted to help reduce infection rate within populations and ultimately helping to reduce deaths due to this virus. A lot of countries, including the United Kingdom, deployed lockdown measures before a herd immunity status could be reached. The implication of this is the potential for a second wave of the COVID-19 viral infection as lock-down measures are being eased [2].

The attention given to older age groups, who were more likely to contract the virus, have severe forms of this disease and more likely to die from it, is well-known. By now, the culture of protection (shielding, social distancing, and use of personal protective equipment) from this virus would seem to be well-known to this older age groups. Where does this leave the younger age-groups?

There are increasing reports about a possibility of having a greater impact of the COVID-19 infection among younger people in the anticipated second-wave of its spread in populations. As lockdown measures were eased, activities driven by younger people like holidays and international trips, school re-openings, dining outs, raves, recreational sites usage would drive a higher chance of the COVID-19 virus spread among them [3].

Should the impact of the second wave of this virus affect younger age groups, the impact on the economy would be felt in the short-term and in the long-term (should increase mortality figures spike in this younger population group). Government regulations have been key in the United Kingdom towards controlling the impact of the COVID-19 virus and many would hope that this continue to be the case as airspaces to countries open.

Our recommendations towards mitigating the impact of a potential second wave of this infection among young people include ensuring increased compliance with anti-COVID-19 spread regulations among them. They will need reinforcing on social distancing and use of face masks. Measures to ensure safe work and school arrangements need to be done. Increased education to these younger age groups about their potential role in the fight against this virus will need to be increased.

Mass testing for the COVID-19 virus may need to be extended to these younger groups, and this should include antibody (COVID-19 IgG) testing. Close observations for infected youngsters to avoid condition deterioration will need to be done. Special consideration for those with risks factors (diabetes, obesity, ethnic minority, deprived community) will need to be reviewed and protective moves considered for them.

Focus research groups to study the infection characteristics on youngsters may need to be set up and may be more recommendations can be generated from them. Task groups to help implement recommendations may need to be created also. These groups may also be tasked with managing a database of COVID-related information for these age-groups. Overall, a concerted effort by all-and-sundry will be required as we navigate our way to a future not debilitated by the COVID-19 virus.

*Corresponding author: Dr. Alamin Alkundi, William Harvey Hospital, Ashford, Kent, United Kingdom, Tel: +447427157067

Accepted: October 17, 2020

Published online: October 19, 2020

Citation: Alkundi A, Momoh R (2020) Younger Age Groups and the Next COVID-19 Wave. Ann Public Health Reports 4(1):76-77 


\section{Highlights}

- The potential risk of a looming second wave of the COVID-19 virus spread in populations (in the United Kingdom, European countries and other places) is a possibility and there are increasing concerns for younger age groups to be more affected.

- Knowledge set, attitudes and practices among these younger age groups that will drive a greater COVID-19 virus spread among them have been identified.

- Regulations, mass testing and creation of research and taskforce groups to manage the impact of this COVID-19 on young people are some out of other potential recommendations that can be embarked on to protect these age-groups.

\section{Conflict of Interest}

The authors declare that they have no conflict of interest.

\section{Funding Source}

None.

\section{References}

1. Wikipedia (2019) Coronavirus disease 2019.

2. Jacqui W (2020) Covid-19: Risk of second wave is very real, say researchers. BMJ 396: 2294.

3. Samuel L (2020) Coronavirus may stick to young people 'like a tornado with a long tail,' WHO warns.

DOI: $10.36959 / 856 / 498$ 